\title{
IDENTIDADES TRANSNACIONAIS E O ESTADO. VIÇO E TEIMOSIA?
}

\author{
ANA PAULA B. TOSTES
}

Entre as mudanças ocorridas no mundo pós-Guerra Fria, no que se refere às alocações de poder e suas consequiências, identificamos que a agenda política contemporânea recepciona fenômenos que se revelam a partir de novos temas da política internacional como a violência organizada de modo subestatal e transnacional ou a crescente ação de organizações internacionais, seja de caráter governamental ou não, seja para realizar fins de natureza econômica, seja para realizar finalidades sociais, humanas ou buscar soluções para problemas ambientais globais. Diante desse quadro, o objetivo do artigo é traçar marcos que nos permitam abordar os novos processos de atuação política extra-estatal e as consequiências da emergência de novos atores políticos para as teorias de relações internacionais.

Diante do surgimento de uma nova sociedade civil global ${ }^{1}$, muitos debates se abrem sobre o "envelhecimento do Estado moderno" e sua possível superação. No entanto, os novos movimentos sociais ${ }^{2}$ preten-

\footnotetext{
${ }^{1}$ Não pretendo neste artigo enveredar-me no debate sobre a imprecisão conceitual ou equivocidades no uso do conceito de sociedade civil global (disputas conceituais e críticas atuais muito se assemelham ao que se passa há décadas com a definição de globalização e da mesma forma me interessa o processo e não a substância de um conceito perfeito, inconteste ou irrefutável). Partirei, assim, de uma definição abrangente e inclusiva que considere a sociedade civil global como um conjunto de atores que interagem socialmente e são emergentes de lutas por novas formas de identidades transnacionais, ativismos transnacionais e extra-estatais, podendo se organizar em grupos de interesses ou através da constituição de instituições não governamentais transnacionais e internacionais. O resultado que interessa é que esse fenômeno se apresenta com crescente intensidade e vem trazendo conseqüências para a pesquisa em relações internacionais, logo, suscita pesquisa empírica e reflexão teórica. 2 São designados como "novos movimentos sociais" os movimentos que passam a se desenvolver em torno de novas temáticas e questões políticas não classistas ou não se referem à relação capital-trabalho e sim com características diversas como: paz, direito das mulheres, direitos humanos, ecologia etc.
} 
dem destruir as bases do Estado, questionam o modelo burocrático moderno de poder ou apresentam alternativas democráticas efetivamente viáveis? Por mais que seja possível e defensável a idéia de que os Estados estão perdendo seu tradicional poder para as grandes, médias ou pequenas organizações econômicas, políticas e societárias que se formam em torno de interesses transnacionais; a pergunta que se coloca é: por que os Estados persistem? São os Estados mais resistentes a mudanças e concertos internacionais e transnacionais do que se imaginava no início do processo de intensificação da globalização?

Ao mesmo tempo em que verificamos o surgimento de novas formas de exercício de poder, seja pelas grandes corporações internacionais, seja pelos indivíduos e grupos de ativistas internacionais, não é possível abandonar a idéia de que os Estados permanecem sendo atores com grande capacidade de centralização de recursos de coação, influência e custeio para a implementação de seus interesses. ${ }^{3}$ Internamente, os Estados apresentam regras democráticas tradicionais (instituições como: divisão de poderes, eleições, representação) que refletem legitimidade. Externamente, os Estados tem apresentado o melhor formato organizacional e burocrático para dar segurança quanto ao cumprimento de compromissos internacionais assumidos.

É importante reconhecer a relevância da recente literatura da teoria democrática e da filosofia sobre o papel da razão, da comunicação e da concepção de uma esfera pública não estatal neste contexto de inovações e resistências. Este artigo pretende colaborar com a reflexão sobre novos temas da política internacional que exigem um diálogo interdisciplinar com as teorias democráticas para que se compreenda melhor a nova configuração do poder dos Estados contemporâneos a partir do debate normativo da relação entre o sistema internacional e a sociedade internacional.

\section{ESCLARECIMENTOS ANALÍTICOS E HISTÓRICOS}

Na década de 1990, o sistema internacional apresentou mudanças de configuração já bastante debatidas pela literatura que admite

${ }^{3}$ Só para exemplificar, algumas das mais importantes e poderosas organizações internacionais atuais, como o Banco Mundial (BM) e Fundo Monetário Internacional (FMI), são constrangidas por uma estrutura formal estadocêntrica. Ou seja, as regras de criação, composição, organização e tomada de decisão não levam em conta interesses ou representações setoriais de sociedades nacionais ou da sociedade civil global, mas sim interesses de coletividades soberanas - mais particularmente, interesses dos países do G7, que detêm atualmente cerca de $45 \%$ dos votos no BM e no FMI. 
a existência de uma "crise do sistema internacional" no contexto de um mundo que deixaria de apresentar "polaridades definidas" para uma realidade política global que poderia ser designada como um sistema de "polaridades indefinidas" (Lafer \& Fonseca, 1997). Sabemos que, desde a década de 1980, os indícios das grandes mudanças que trariam as novas tecnologias de transporte e comunicação, à proporção de seu acesso, levavam, em alguns casos, a um certo otimismo no que dizia respeito à possibilidade da construção de um modelo de ordem internacional multipolar, com a participação crescente de atores não governamentais, por isso, mais democrática. O fim do século, no entanto, rapidamente deixou-nos concluir que novos temas de política internacional e novos elementos de consideração na distribuição do poder tiraram a clareza e a simplicidade das prospectivas de mudança. ${ }^{4}$ Assim, considero fundamental o retorno aos clássicos que tratam do tema para que possamos mapear normativamente um debate mais complexo.

Para Aron (1996), a característica principal do sistema internacional é a "configuração de forças". Antes de 1945, segundo Aron, nenhum sistema de Estados tinha chegado a abranger todo o mundo, assim, para definir a "configuração de forças" o autor compara as duas mais simples: bipolaridade e multipolaridade. Isso porque Aron compreende que há uma tendência e uma ambição que leva a duas configurações modelares: os grandes Estados tendem a orientar sua ambição de modo a modelar a conjuntura, enquanto os pequenos Estados (também por razões estratégicas) tendem a adaptar-se a uma conjuntura que essencialmente não depende deles.

Da definição clássica realista de Aron, é possível destacar vários elementos: o sistema internacional é conduzido por interesses de atores estatais (ainda que o autor admita a existência de outros tipos de atores), o elemento específico de relacionamento desses atores é a competição e a última razão da competição entre as unidades políticas é o apelo

\footnotetext{
${ }^{4} \mathrm{O}$ que fez levar, inclusive, à valiosa contribuição de Joseph Nye sobre a consideração analítica da política internacional em diferentes níveis. Para Nye, a complexidade da política internacional em um mundo interdependente é mais bem compreendida a partir da perspectiva de um jogo tridimensional em que categorias de poder são exercidas ao mesmo tempo de modo autônomo e interveniente, com comunicação e interferência entre elas. Esta noção permitiria conceber um exercício unipolar de poder norte-americano, por exemplo, no primeiro tabuleiro (que se refere ao poder militar-estratégico), mas no segundo e terceiro tabuleiros (que se referem, respectivamente, ao poder econômico e às relações transnacionais) o exercício da dominância americana é limitado ou perpassa por formatos não tradicionais, segundo a perspectiva da realpolitik.
} 
à violência. Para o autor, a competição real leva à redução dos atores, logo, Aron não imaginaria uma competição com características de horizontalidade indefinida, como fazem teóricos da interdependência, como Robert Keohane e Joseph Nye. Além disso, novos problemas antes tratados no âmbito nacional hoje são transnacionais, globais ou vem ser tratados comparativamente.

Um dos problemas hoje associados à globalização que demanda soluções transnacionais é o aumento da pobreza e o risco de não crescimento de países não globalizados. Em atenção a isso, o Banco Mundial publicou resultados de pesquisas recentes sobre a relação entre globalização, crescimento e pobreza, realizadas sob sua coordenação, que confirmam a crescente dificuldade de crescimento e desenvolvimento de Estados que possuem menos de 3 milhões de habitantes e ainda não se integraram. Estes países não possuem recursos de competição no mercado internacionalizado e provavelmente não se recuperarão, segundo os pesquisadores. Por outro lado, o Banco Mundial não aceita a tese do aumento da pobreza nas últimas décadas. Ou seja, segundo a interpretação dada pelos pesquisadores e analistas sobre os índices de pobreza é necessário - antes de tudo - definir pobreza no mundo atual. Em resumo, isto se dá, principalmente, porque o Banco Mundial admite uma concepção multidimensional de pobreza que não reconhece apenas determinantes de desempenho econômico, mas outros aspectos da vida social e da qualidade de vida. Nesse contexto de considerações, a pobreza era maior no século XIX do que no século XXI, onde condições mínimas de cidadania, saúde, educação, informação e perspectivas de ascensão existem. ${ }^{5}$ Para argumentar que, apesar da grande desigualdade (acelerada, principalmente, ao longo do século XIX), a pobreza diminuiu, a tese do Banco Mundial se pauta em uma análise histórica da globalização que aborda três fases como "três ondas" de desenvolvimento.

Em síntese, a "primeira onda" seria a do período de 1870-1914, marcada por avanços tecnológicos (com a expansão das ferrovias e mudança dos barcos à vela pelos navios à vapor) ${ }^{6}$ que viabilizaram uma combinação de custos decrescentes de transportes com redução de barreiras tarifárias, diante das enormes oportunidades para produção e exportação de produtos que exigiam terras abundantes. Esse é um período de

5 Para mais detalhes, cf. Globalização, crescimento e pobreza, São Paulo, ed. Futura, 2002.

6 Podemos complementar citando mais um importante fato do início da globalização: a expansão e o aperfeiçoamento do uso do telégrafo. 
muitas transformações mundiais com a expansão da Revolução Industrial pelo mundo. Antes restrita apenas à Inglaterra, na segunda metade do século XIX, essa fase da Revolução Industrial é marcada por grandes inovações tecnológicas enquanto no setor de energia mudaram as relações de produção e de serviço. Esse mesmo período também é identificado por Boli \& Thomas (1997) como sendo um marco significativo para se mapear o povoamento das Organizações Não Governamentais. Com exceção dos períodos das duas grandes guerras mundiais - quando há um declínio de criação e um aumento de falências de instituições, desde 1875, mais de 25.000 organizações internacionais privadas, sem fins lucrativos, vêm povoando o cenário internacional (cf. Figura 1., p. 176, American Sociological Review, v. 62). Entre 1914-1945 considera-se um recuo na tendência globalizante do mundo em função do nacionalismo, das guerras, da Depressão no período entre guerras e da reversão da política comercial (apesar dos contínuos avanços tecnológicos causadores de redução de custos de transporte - nesse período o custo do frete marítimo caiu 1/3).

Uma "segunda onda" teria se iniciado com o fim da Segunda Guerra mundial. Um ciclo se completou entre 1945-1980, que é o período embrionário da introdução de uma nova economia e um novo tipo de comércio, com a especialização dos países em nichos de mercado e produção. O marco da década de 1980 é dado pela "revolução tecnológica da microinformática", que trouxe suas implicações para a comunicação e transporte em nova escala de possibilidades.

Sobre os fenômenos que culminaram na "terceira onda" da globalização (que se iniciou em 1980 e não acabou), podemos encontrar um amplo debate que envolve os problemas do poder das grandes corporações internacionais e as transformações pelas quais a economia mundial passou, com graus de defesa da perda relativa (baixa ou alta) do poder do Estado. Esse é um debate longo e muito bem explorado por autores como Gilpin (2001) e Strange (1996). Esses autores são referências pontuais para a oposição de argumentos a respeito das condições e conseqüências da relação entre o poder dos Estados e a globalização da economia desde o período da Guerra Fria.

Na verdade, em seu livro Global Political Economy (2001), Gilpin faz uma autocrítica em relação a sua obra anterior The Political Economy of International Relations, de 1987, voltando-se para uma perspectiva estadocêntrica da política internacional. Gilpin constata que o cenário pós-Guerra Fria não trouxe uma diminuição da importância da política doméstica, revertendo-se com isso a uma leitura mais realista a 
respeito da manutenção do poder do Estado diante da "terceira onda" da globalização. Essa terceira e última fase é marcada, segundo o Banco Mundial, entre outros fatores, pela expansão das conseqüências da globalização para amplos setores da vida social e dos temas políticos. É incontestável que o aumento de interconexões e influências recíprocas no âmbito da convivência internacional extrapolou o setor da economia, principalmente na última década. Mas se o Estado permanece exercendo poder no sistema internacional, é provável que venha se adaptando bem às mudanças de suas funções. Até mesmo porque, em certos casos, pode ser de interesse do Estado perder obrigações excessivas.

Podemos buscar uma saída para o debate infértil em torno de argumentos de defesa ou não da novidade de um sistema político em que os atores são variados e destacar que os Estados sempre operaram dentro de um sistema global de interação política e, numa certa medida (conforme os recursos tecnológicos e mesmo coercitivos de cada período histórico), sempre precisaram conviver com outras instâncias de poder. Nessa linha de pensamento, a existência de agências não estatais na sociedade internacional, assim como a importância das relações internacionais, não seria uma novidade das últimas décadas. Assim, os anos que se seguiram à Guerra Fria nos dão subsídios para conferir que a economia mundial não diminuiu a importância determinante da economia e da política domésticas (Gilpin, 2001). Para Gilpin, é preciso reconhecer a importância concomitante da economia mundial e da economia política internacional para que se faça uma clara distinção entre os interesses políticos nacionais (determinados por elites domésticas) e os propósitos de cooperação entre os Estados. Segundo Gilpin (2001), o funcionamento da economia mundial é determinado pelo mercado e pelos Estados nacionais, entretanto, ele destaca que a economia é mais dependente dos desenvolvimentos sociais e políticos do que os próprios economistas admitem. Esta inter-relação entre a economia e a política leva-nos a concluir, segundo os argumentos de Gilpin, que os Estados e o mercado estão integrados: os Estados ainda mantêm o monopólio do poder normativo jurídico ao mesmo tempo em que princípios do mercado impõem agendas internacionais. ${ }^{7}$

${ }^{7}$ Para Gilpin, os Estados modernos ainda são altamente autocentrados e raramente se mostram solidários com os demais. Esta afirmação é de base realista e não normativa, pois é claro que seria preferível um mundo em que a "governança", em qualquer nível, global ou nacional, substituísse a lógica do egoísmo anárquico. Entretanto, para o autor, o fato é que não é possível construir-se "governança" sem uma identidade comum, logo a crença na sua substituição pela primazia do Estado-Nação pode ser vista como uma utopia (Gilpin, 2001, p. 402). 
Além disso, embora os temas da economia global sejam amplos e cada vez mais debatidos, atores e interesses não econômicos e não governamentais também ganharam importância no processo de interdependência da "terceira onda" da globalização. Valorizemos ou não os debates, é fato que entraram na agenda contemporânea temas como identidade, cultura, valores, idéias a respeito de uma sociedade civil global e de uma nova esfera pública. ${ }^{8}$ Os movimentos sociais encontraram novas formas de ativismo e novos dilemas, tendo deixado de se configurar a partir de questionamentos da ordem do capital (de caráter fundamentalmente classista) ou do trabalho apenas. São chamados "novos movimentos sociais" estes que se diferenciam em seus objetivos e práticas, compreendendo reivindicações que podem circular desde as demandas setoriais e classistas até questões de gênero, comportamento sexual, outros universos de identidade, respeito a diferenças socioculturais, direito de emigrantes etc. O que há de comum entre "novos" e "velhos" movimentos sociais é a perseguição de um projeto coletivo como saída do individualismo pela experimentação de ações solidárias em nome de interesses que são públicos, mas não classistas e não nacionais. O direito se torna importantíssimo para a construção de vias de ação e integração entre grupos sociais que defendem interesses parciais, assim como a criação de organizações internacionais que também dependem de regras e reconhecimento jurídico para que adquiram poder e/ou influência transnacional. Se a institucionalização é o caminho da democracia contemporânea, o aumento do estabelecimento de tratados internacionais pode ser um revestimento para este caminho.

A existência de regras internacionais é causa e conseqüência ao mesmo tempo da expansão da atuação da sociedade civil global. Keck \& Sikkink (1998) já demonstraram como o ativismo transnacional foi fundamental para a regulação de direitos no âmbito doméstico. Glasius \& Kaldor

\footnotetext{
${ }^{8}$ Ao analisar o associativismo na América Latina e as mudanças ocorridas a partir da década de 1970, Avritzer (1997) destaca que não há que se falar de uma nova esfera pública, mas sim de novas formas de ocupação da esfera pública, pois defesas de interesses genéricos de classe ou de uma identidade genérica de povo caracterizam organizações com tendência à homogeneização dos interesses representados e isso foi o que mudou. Podemos acrescentar que essa foi uma tendência global, interesses genéricos foram substituídos pela pluralidade e particularidade de demandas - assim, a luta por direitos diferenciados é que passou a atender, em última instância, ao interesse público. Segundo dados organizados por Keck \& Sikkink (1998), entre 1953 e 1993, houve um aumento total de 5 vezes o número de ONGs voltadas para temas-chave como: direitos humanos, ordem mundial, lei internacional, paz, direito das mulheres, meio ambiente, desenvolvimento, raça e etnia, esperanto (Cf. Keck \& Sikkink, 1998, tabela 1, p. 11).
} 
(2002) reforçam a relação entre a expansão da sociedade civil global e o direito internacional, pois a sociedade civil é ao mesmo tempo dependente da existência de regras internacionais e a principal impulsionadora da adoção de enforcement das regras internacionais. ${ }^{9}$

Movimentos sociais, ativismos e organizações de setores das sociedades sempre existiram com objetivos contextualizados, estruturados segundo demandas locais e condições relativas às realidades históricas de cada época e lugar. Em suma, mais cedo ou mais tarde, com mais ou menos intensidade, desde o início do sistema de Estados (se considerarmos o aperfeiçoamento da representação e divisão de poderes, que só começa a partir da Revolução Gloriosa inglesa e demora mais de um século e mais uma grande revolução para ser introduzida no continente europeu), formas desestatizadas de organização de interesses surgiam paralelamente aos Estados e ainda assim eles "venceram" como modelos institucionais privilegiados.

Antes do Estado moderno, grupos de interesses resolviam seus problemas ou assumiram lutas por direitos coletivos a partir de mecanismos associativos e organizacionais de caráter particular ou público (exemplos: organizações sindicais e maçonaria). Sabemos que a França do Antigo Regime era um campo de interlocuções e representações locais e setoriais que foram proibidas a partir da constituição da República. Tocqueville é um crítico do modelo de representação centralizada de interesses do Estado francês no século XIX (cf. $O$ Antigo Regime e a Revolução e Democracia na América) exatamente por isso - por ser contra a homogeneização de interesses e defender a liberdade e a realidade das diferenças. Com isso podemos reforçar a idéia de que há muita ingenuidade nas afirmações que ignoram o processo histórico conflituoso que está no gérmen dos Estados ou a capacidade associativa sub-estatal.

Walzer (1999), ao criar cinco tipos ideais para explicar regimes de tolerância, reconhece o Estado-Nação, não como um modelo em que há uma nação homogênea sob um Estado burocrático, mas sim como um regime de tolerância que se equilibra graças à dominação de um grupo sobre os demais coexistentes no mesmo território. O grupo nacional dominante exerce seu poder moldando a vida pública, determinando a re-

${ }^{9}$ Segundo dados apresentados e organizados em gráfico por Glasius \& Kaldor (Cf. Gráfico R8b, 2002, p. 291), pode-se observar um aumento extraordinário de tratados concluídos e ratificados pelos Estados sobre os mais variados temas e especialmente sobre direitos humanos, direitos humanitários e meio ambiente nas décadas de 1980 e 1990. 
ligião oficial, reproduzindo sua cultura através das instituições e tolerando as minorias em nome do respeito aos indivíduos, que "são concebidos como estereótipos: primeiro como cidadãos, depois como membros desta ou daquela minoria."

No âmbito da história e da cultura, o Estado-Nação não é neutro; seu aparato político é uma máquina de reprodução nacional. Grupos nacionais buscam a condição de Estado justamente para poder controlar os meios de reprodução. (Waltzer, 1999, p. 34-35)

Identificar uma crise como a do Estado-Nação sem considerar os próprios limites que sempre existiram para a consecução desse projeto é como pressupor que os Estados modernos estiveram, por um longo período, exercendo um papel perfeitamente conduzido, de centralização de poder e homogeneização de cultura, identidade e nacionalidade. A própria prevalência do modelo do Estado-Nação como regra foi fruto de disputas e dissidências, logo, ao mesmo tempo em que paralelamente aos Estados, atividades políticas e econômicas sempre concorreram com o seu poder centralizador, o Estado vem resistindo desde seu surgimento até a era da globalização do século XXI. Com tudo isso, quero dizer que estamos tratando de uma disputa contínua de poder, em que os Estados vêm se saindo muitíssimo bem. Assim como internamente, as nações dominantes em um Estado raramente são as únicas, mas necessariamente são as mais fortes, na sociedade internacional de Estados, esses nunca foram os únicos atores e nunca serão, mas têm conseguido ser os mais fortes entre os demais.

\section{SOCIEDADE VERSUS SISTEMA INTERNACIONAIS}

Charles Tilly (1996, p. 238) afirma que os Estados europeus se constituíram como um sistema na medida em que passaram a interagir entre si com regularidade e à proporção que sua interação cada vez mais passou a afetar comportamentos recíprocos. Essa não é uma afirmação polêmica, mas nos remete à introdução da noção de sistema e, em contraste, à noção de sociedade de Estados. Aron, Waltz, Bull ou Keohane não polemizam sobre a existência da interação entre uma pluralidade de Estados ao identificarem teses diferentes a respeito do impacto, das condi- 
cionantes e das conseqüências dessa interação. Podemos dizer mais: falar dessa interação é falar de razões, condições e conseqüências da existência de uma ordem internacional. Isso significa que todos esses autores apresentam perspectivas próprias a respeito da estabilidade e riscos de instabilidade da ordem política mundial.

Voltando a Tilly (1996), ele defende que os Estados jamais foram os únicos atores internacionais, porque forças de influência e pressão internacional sempre foram players no processo desse jogo. Forças religiosas, o mercado mundial, o capital internacional, as atividades industriais territorialmente dispersas, as organizações transnacionais do início da modernidade, os novos blocos econômicos, ONGs, enfim, instituições internacionais em geral, muitas vezes estabelecem limitações adicionais às opções práticas disponíveis à soberania dos Estados (Joseph \& Falk, 1992, p. 252-253). Charles Tilly (1996, p. 48) inclui nesses casos a existência de organizações ou redes mundiais de negociantes de mercadorias caras e ilegais, como drogas e armas forças marginais de influência que variam com a História mas que, de fato, sempre existiram. Por tudo isso, concluímos que forças legítimas e ilegítimas sempre produziram efeitos na configuração de forças do sistema internacional desde o surgimento do próprio Estado. A modernidade é marcada pelas "revoluções protestantes" (Reforma, revoluções inglesas: puritana e gloriosa etc.), pela Paz de Westphalia e por disputas de influência e domínio - esse é o contexto da configuração de forças que faz emergir os Estados.

As condições contemporâneas de interdependência e globalização não trouxeram necessariamente uma agregação pacífica ou uma integração solidária entre as culturas e os diversos sistemas econômicos. Assim, podemos dizer que o que há de novo é que esse aumento das interconexões e influências recíprocas no âmbito da convivência internacional extrapolou o setor da economia, principalmente na última década, com a aceleração e facilitação do acesso às novas tecnologias e da microinformática, atingindo assim amplos setores da vida social e penetrando o cotidiano das relações pessoais: ajudando a construir preferências e intervindo nos comportamentos sociais - não apenas afetando as grandes relações de poder e a política, mas com certeza, afetando micro relações de intimidade, de conformação de opiniões e de identidades transnacionais a partir da facilitação de associações e relações interpessoais, por conta da ampliação do acesso à informação e à comunicação. 


\section{Uma revisão clássica da tradição realista: Waltz}

$\mathrm{O}$ neo-realismo surge para oferecer respostas satisfatórias às mudanças do mundo Pós-Guerra Fria, o que o realismo não parecia capaz de fazer. Não se pretendeu negar o realismo como paradigma, mas superálo a ponto de enfrentar as críticas à esterilidade que as teses clássicas passaram a receber. Nessa direção, leituras diferentes do neo-realismo surgiram para superar as meras justificativas ideológicas ou explicações históricas sem caráter de cientificidade.

Kenneth Waltz propõe uma perspectiva sistêmica para a análise das relações internacionais e para isso sustenta que são condições da balança de poder que influenciam as condutas e as escolhas dos Estados. Atributos dos Estados, tais como suas instituições, a natureza das regras políticas, características culturais, ideológicas etc., contam pouco na determinação da configuração do sistema. A proposta de Waltz explicitada na Teoria das Relações Internacionais ${ }^{10}$ não é a de explicar as mudanças nas relações internacionais, porque as considera raras, portanto "difíceis de acontecer" e "irrelevantes para a sua teoria". Interessa a ele explicar porque a oligarquia é constante ou qual seria o fator sistêmico capaz de justificar a continuidade desse modelo de equilíbrio em que o princípio ordenador é a anarquia (regra da auto-ajuda, competição etc.). A situação anárquica dos Estados faz com que, recorrentemente, se formem "balanças de poder" (Waltz, 2002, p. 178) que retratam o sistema internacional, ou seja, a lógi ca de interação entre os atores, segundo suas capacidades.

Apesar dos Estados serem funcionalmente semelhantes, eles diferem muito nas suas capacidades, dessas diferenças, segundo Waltz, algo semelhante a uma "divisão de trabalho" se desenvolve. Como o que mais marca um sistema de auto-ajuda é que cada uma de suas unidades gasta boa parte de seus esforços - não perseguindo o seu próprio interesse, mas se protegendo dos outros - a especialização (como a que se dá na "divisão de trabalho") funciona como uma vantagem para todos (Waltz, 2002 , p. 147 ss.). Em um contexto desse podemos dizer que a diferença e desigualdade são redimidas pela sobrevivência.

Um sistema de auto-ajuda (baseado no interesse próprio) é um sistema de alto risco - risco de falência, no domínio econômico, de guerra, em um mundo de Estados livres. Assim como ocorre com as pessoas, o convívio entre Estados se torna inseguro na proporção em que estes dese-

${ }^{10}$ A publicação original é da década de 1970. 
jem liberdade: "se a liberdade é desejada, a insegurança tem que ser aceite" (Waltz, p. 156). ${ }^{11}$ Waltz rejeita a idéia de sociedade internacional, pois a estrutura constitui preferências e constrangimentos aos agentes que interagem, e não são elementos valorativos nem elementos baseados em princípios imateriais que levam coletividades estatais a eleger suas preferências (e sim a tendência egoísta dos Estados somada a sua posição relativa à configuração de forças no sistema internacional). ${ }^{12}$

\section{Lições liberais}

Segundo a perspectiva racionalista de Hedley Bull, os atributos essenciais do sistema contemporâneo de Estados são: a pluralidade de Estados e a interação entre eles, que pode vir a levar à aceitação de regras e interesses comuns, com respeito às quais eles formam uma sociedade de Estados. É claro que, teoricamente, é possível imaginar-se uma pluralidade de Estados que não interagem, formando-se ilhas sem muito ou com raros contatos e interferência ou uma interação tão frágil a ponto de não se constituir uma "sociedade internacional", segundo sua concepção da expressão. Ou seja, Bull admite, em tese, a existência de uma pluralidade de Estados em interação mas sem valores e interesses comuns, isso naturalmente pressupõe a existência de conflitos potenciais, limitados por capacidade bélica mas não pelas vontades, em exemplo ao estado de natureza de Hobbes.

Enfim, para Bull, o sistema de Estados real contemporâneo possui elementos de sociedade, embora com bases precárias (Bull, 2002, p. 289), pois apesar "da ilusão de fortalecimento do direito internacional e a multiplicação de organismos internacionais desde o princípio da Primeira Guerra Mundial vem ocorrendo um possível declínio no consenso sobre os interesses e valores comuns dentro do sistema de Estados. (...) É fácil imaginar que nas próximas décadas essas tensões afetarão o que dela restou, reduzindo-a ainda mais, de forma drástica, e podendo até mesmo fazer com que desapareça de todo.” (Bull, 2002, p. 289).

\footnotetext{
${ }^{11}$ Note-se aí uma concepção hobbesiana de liberdade, que se concilia com a tendência expansionista dos Estados para o argumento realista.

12 Não é por acaso que, muito didaticamente, Waltz se dedica a distinguir teorias reducionistas de teorias sistêmicas, para afirmar que nos casos em que fatores de interação são determinantes das ações dos atores em questão, assim como se dá no sistema de Estados, só uma teoria sistêmica seria capaz de captar o retrato da realidade política.
} 
Continuando o debate a respeito não mais da eventual crise da sociedade internacional como Bull compreende, mas agora do sistema de Estados, é curioso que o autor já aponta como sinal de risco ao sistema de Estados "a restauração da violência internacional privada", ou seja, o recurso à violência em escala internacional por grupos não-estatais e sua afirmação do direito de praticá-la - rejeitando o monopólio do uso legítimo da violência e coerção reivindicado pelos Estados modernos (Bull, 2002, p. 300-301). É certo que Bull exemplifica essa violação de monopólio por organizações internacionais como a ONU, mas atualmente já conhecemos formas mais drásticas de exemplificar a tese de Bull. Por fim, embora contribua enormemente ao debate sobre o sistema de Estados e a sociedade internacional e suas eventuais crises, sem dúvida, Bull não crê que o sistema de Estados esteja sendo substituído por outra ordem em que atores não interagem ou conflitem completamente.

É baseado na consideração de que os Estados não são excessivamente egoístas e expansionistas, como pressupõem os realistas, que Bull (2002) focaliza diferenças e semelhanças entre o sistema anárquico internacional e o sistema societário nacional. $\mathrm{O}$ fato é que o autor crê que historicamente há uma interação identificável no sistema contemporâneo e a prova disso é a existência de instituições internacionais comuns.

Outras perspectivas racionalistas de raízes liberais são as de Keohane e Nye. ${ }^{13}$ Esses autores destacam a interdependência como fator de aumento de conflito e necessidade de cooperação, ao mesmo tempo em que dialogam e discordam, em parte, da perspectiva estruturalista de Waltz que não permite uma abordagem individual-metodológica para se realizar análises de fenômenos internacionais. Contudo, Waltz (2002) critica agudamente Keohane, atribuindo à noção de "associação de interesses" (típica dos liberais ingleses mentores da idéia de laissez-faire) à concepção de interdependência. Segundo Waltz, a interdependência faz pressupor que todos os atores têm os mesmos recursos para competir ou cooperar, logo, condições iguais de interferência e influência no status político alheio. Na verdade, Waltz parece identificar um descabimento da noção de interdependência tal como é conduzida na tese de Keohane, como se esta não fosse um conceito

13 Podemos dizer que estes autores não abandonaram pressupostos do neo-realismo nem do liberalismo - para gerar a perspectiva teórica que vem sendo designada como institucionalismo neoliberal. Ou seja, a base estatal do sistema internacional não é abandonada, mas a ela é acrescida a importância de instituições no processo de interdependência - o que se verifica desde a passagem da década de 1960 para a década de 1970. 
construído que ignora a importância da capacidade diferenciada dos atores. Ao comentar a crescente atribuição do conceito de interdependência à sen sibilidade, Waltz é afiado em sua crítica ao atribuir tal associação ao senso comum e finalmente propõe uma definição "mais útil do termo: interdependência como vulnerabilidade mútua"(2002, p. 193).

É, no mínimo, instigante notar os fundamentos da acusação de Waltz de que a atribuição do conceito de interdependência à sensibilidade é uma tendência economicista de se analisar as relações internacionais. A idéia de que há uma profunda interdependência no mundo e que sua prova seria a de que qualquer coisa que aconteça em qualquer lugar pode afetar alguém deveria nos recordar, segundo Waltz, à teorias de mercado. Devemos recordar o mercado livre e auto-regulador descrito pelos economistas liberais do século XIX, que deve satisfazer os interesses de todos a longo prazo. Entretanto, “o capital e a mão-de-obra movimentam-se livremente, os bens nem tanto, (...)" (Waltz, 2002, p. 194). "A concepção comum de interdependência omite as desigualdades, econômicas ou políticas. E, contudo, a política é desigualdade. O estudo da política, as teorias sobre política, e a prática da política sempre versaram sobre as desigualdades, quer entre grupos de interesse, entre comunidades étnicas e religiosas, entre classes, ou entre nações." (2002, p. 198).14

Essa visão de Waltz também reforça a diferença entre sistema internacional e sociedade internacional. Desde uma visão realista, esses conceitos não se confundem e se a desigualdade é um fundamento importante da anarquia internacional, jamais se fundirão. O conceito de sociedade internacional frisa o consenso de regras mínimas de convivência expressadas em instituições históricas ou formais. A distinção mais clara desses conceitos foi descrita por Hedley Bull, por reunir em uma mesma expressão a aceitação de uma anarquia e de uma sociedade ao mesmo tempo: sociedade anárquica - ou porque não dizemos: igualdade na diferença. 15

Segundo Bull, há um sistema internacional (ou um sistema de Estados) "quando dois ou mais Estados têm suficiente contato entre si, com suficiente impacto recíproco nas suas decisões". De outro lado, há uma sociedade internacional (sociedade de Estados) quando um grupo de Estados, conscientes de certos valores e interesses comuns, forma uma

${ }^{14}$ É claro que esta crítica de Waltz pode ser refutada, pois se trata de uma leitura cética dos reais e complexos argumentos e conceitos dos pesadores do intitucionalismo neo-liberal.

15 Isso nos faz lembrar imediatamente o casamento liberal entre igualdade jurídica e individualismo, ou ainda a velha máxima tocquevilliana: igualdade na liberdade. 
sociedade, no sentido de se sentirem ligados, no seu relacionamento, por um rol comum de regras e instituições. Na verdade, seu conceito de sistema internacional não difere do conceito dos autores hobbesianos como Aron, mas seu conceito de sociedade internacional (que é uma sociedade de Estados) inova ao reconhecer que instituições internacionais geram e refletem ao mesmo tempo comportamentos sociais, hábitos, costumes, tradições como a diplomacia ou a aceitação de um direito internacional público. $\mathrm{O}$ autor identifica a efetiva existência, na história dos Estados, de regras e instituições e o mínimo consenso sobre elas - o que permitiu a emergência de uma ordem entre os Estados. Assim, aquilo que poderia parecer um contra-senso (a anarquia hobbesiana e sociedade) se junta para se formar o núcleo duro do legado de Bull. Ele considera a falta de centralidade e hierarquia (o que caracteriza a anarquia), mas identifica (não simplesmente defende normativamente) a existência de instituições internacionais que revelam comportamentos gerais e expectativas de segurança e previsibilidade nas ações dos Estados.

Uma concepção iluminista da razão humana (e não estratégica como se mostra a racionalidade realista) dá a liga na teoria de Bull. É fundamental que se esclareça: o pensamento de Hobbes é tão racionalista quanto o de Locke. O realismo clássico defende a ação racional dos atores tanto quanto o liberalismo ou o racionalismo de Bull. A diferença está na capacidade intrínseca da razão, ou seja, na própria concepção de racionalidade, que implicará expectativas de comportamentos diferentes devido a motivações também diferentes. Agir racionalmente para Hobbes é calcular a relação custo-benefício da ação, diante da falta de uma situação naturalmente favorável ao seu próprio e mais egoísta interesse. Para o pensamento liberal, a razão é minimamente moral, logo, o homem é naturalmente sociável mesmo quando age racionalmente. A razão pressupõe valores, assim, ao mesmo tempo em que o ator é individualista e estratégico, ele reconhece interesses comuns que constituem uma ordem natural mínima.

$\mathrm{Na}$ verdade, o que disputam realistas e liberais é a razão da ordem, ou seja, para o realismo a ordem é um equilíbrio de forças e riscos, para os liberais ela é a prova de um ethos societário. Por outro lado, as instituições internacionais identificadas por Bull são menos abrangentes e flexíveis do que as instituições de Keohane, assim também como os atores para Keohane são menos sociáveis e mais egoístas do que para Bull.

Para Keohane, instituições são conjuntos de regras (formais $e$ informais) que persistem no tempo e prescrevem padrões de conduta, restringem as atividades dos atores e configuram expectativas. Assim, se- 
riam instituições internacionais: i) organizações intergovernamentais formais ou não governamentais internacionais; ii) regimes internacionais (regras explícitas acordadas entre Estados sobre conjuntos específicos de temas de relações internacionais); 16 iii) convenções (no sentido dado pela teoria social e não do direito internacional, logo, são regras e entendimentos implícitos e informais que configuram expectativas dos agentes e permitem coordenar comportamentos sem regras explícitas). ${ }^{17}$

Keohane compartilha com Waltz a perspectiva de que agentes não estatais são subordinados aos Estados e que é preciso explicar a regularidade do comportamento dos Estados no sistema internacional anárquico. Ou seja, ambas as abordagens teóricas visam explicar o comportamento dos Estados através da compreensão da natureza do sistema internacional. No entanto, enquanto o estruturalismo de Waltz valoriza os recursos (econômicos e produtivos) dos Estados para compreender sua capacidade, o institucionalismo neoliberal destaca também as convenções como elementos fundamentais de política mundial. Isso porque, expectativas de comportamento e a coorde nação convencionada de ações e práticas internacionais são consideradas tão fundamentais na condução da ação estratégica dos agentes quanto são os recursos de poder das unidades.

Embora Keohane mantenha uma postura teórica de linhagem realista, certamente, seu afastamento do hobbesianismo é maior do que o de Waltz. Na verdade, o que Waltz desaprova na tese de Keohane sobre o conceito de interdependência, conforme já foi detalhado, é sem dúvida sua vertente liberal. Contudo, Keohane ainda busca justificar a diferença entre cooperação e harmonia (que corresponderia à noção de "associação de interesses") para caracterizar a tendência à cooperação que ele reforça em seus argumentos como uma forma de superação dos interesses divergentes, uma adaptação à situação de conflito diante da incerteza e da assimetria. Essa adaptação é fundamental porque pode haver discórdia mesmo quando há interesse comum, logo, só a institucionalização poderá trazer segurança à ação coletiva. Diante de um mundo interdependente, citando Alice no País das Maravilhas de Lewis Carroll, o autor diz que "puede ser necesario seguir corriendo más rápido para poder quedarse quieto." (1988, p. 18). Chamo esse impasse de "dilema de Alice", pois é preciso cooperar mais para manter um mesmo grau de conflito em um mundo interdepen-

16 São exemplos do autor o regime monetário internacional estabelecido em 1944 (Bretton Woods) e o regime do Direito dos Mares.

${ }^{17}$ São exemplos: o princípio da reciprocidade ou a imunidade diplomática. 
dente. Isso deixa bem claro que os mecanismos cooperativos, mesmo baseados no papel condicionante e impactante de idéias, valores e identidades nas relações internacionais, não resolveria a tendência genética ao conflito. Logo, a defesa desses aspectos não tangíveis da política se faz dentro de cálculos estratégicos e de competição por poder. 18

Sobre a crescente importância do papel das identidades, valores compartilhados e crenças nas relações internacionais se somam os debates sobre a emergência de novos atores internacionais e de uma sociedade civil global, que explicaria uma nova tendência para se pensar a relação entre o sistema de Estados e a sociedade internacional. Incluindo-se a importância das instituições e dos indivíduos ao mesmo tempo (como se confluíssem idéias naturalmente associadas ao racionalismo liberal e ao idealismo utópico separadamente), é possível considerar a importância das idéias e formas de solidariedade na política internacional.

O reflexo da importância e da necessidade de análise desse fenômeno fez com que se integrassem áreas da teoria democrática e da filosofia com a finalidade de se considerar o papel da razão, da comunicação e a concepção de uma esfera pública não estatal no contexto do aparecimento de novos temas no campo das relações internacionais. Além, é claro, do questionamento das novas formas de expansão e coalisão de poder na política internacional. Tudo isso nos desafia a retomar o debate normativo da relação entre o sistema internacional e a sociedade internacional.

Atualmente, novos processos, novos atores e novos temas desafiam o poder tradicional dos Estados, mas o monopólio do uso legítimo da força e o paradigma da soberania na ordem jurídica e política internacional ainda não foram substituídos. Deixando-se como tarefa para os teóricos a busca de novos conceitos e teses sobre poder, soberania, democracia, fronteira etc.

Só uma perspectiva histórica da formação dos Estados europeus pode contribuir para a análise crítica a respeito dos problemas da democracia

18 Não é objetivo deste artigo fazer uma abordagem construtivista sobre o tema das identidades, especialmente porque não pretendo me deter na origem das idéias ou das instituições. Admitindo que as idéias e identidades forjam regras, instituições e regimes, pretendo focalizar o impacto e a operacionalidade das instituições entre si e perante o Estado. A abordagem construtivista não se opõe nem ao realismo nem ao liberalismo e tal como vem sendo descrita e explicada por Alexander Wendt (1999), não se trata propriamente de uma teoria política, mas uma teoria social aplicável às relações internacionais de modo a permitir investigações empíricas interessantes (Cf. tb. Risse-Kappen, 1994; 2000, Adler,1992; Finnemore,1996). Em suma, considero a perspectiva construtivista de importância fundamental para a compreensão da emergência da sociedade civil global - ainda que não seja o foco deste artigo. 
política contemporânea. Uma tal perspectiva revela que o aparecimento do Estado como forma institucional dominante e a consolidação do Sistema de Westphafia, não foram eventos casuais nem consequiências necessárias de fatos passados, mas sim o resultado de disputas acirradas de autoridade. Segundo Tilly, "pareceram tão naturais os Estados nacionais, a expansão dos exércitos nacionais e a longa hegemonia da Europa que os estudiosos raramente indagam por que as suas alternativas plausíveis não prevaleceram no continente europeu" (Tilly, 1996, p. 50). Mas, na verdade, a prevalência dos modelos modernos de soberania e de Estado foi o reflexo de que havia vantagens circunstanciais nessas fórmulas de organização teórica e prática para justificar o poder e não nas outras concorrentes (Spruyt, 1994) - se assim foi no momento de seu surgimento, de alguma forma, continua a ser vantajoso o modelo estatal. Falta repensar conceitos, como o de "fronteira" - é o que faz Kratochwill (1986), que apresenta uma forma mais eficiente para se traçar atualmente as trajetórias do exercício do poder e da influência coercitiva de um Estado. Segundo o autor, mais importante para a o exercício do poder soberano dos Estados, atualmente, não é o poder que se verifica nas suas fronteiras territoriais ou a partir delas, mas, sim nas suas "fronteiras funcionais". Assim, segundo o autor, continua a ser possível identificar-se uma fronteira política, desde que não levemos em conta aspectos meramente físicos ou concretos na análise do exercício do poder. É o alcance e a influência de um Estado nas suas relações internacionais que são determinantes, atualmente, de sua força e capacidade de crescimento e desenvolvimento.

Em certa medida, é inegável que uma rede de estruturas de "autoridades justapostas" e "fidelidades em conflito" já compunha a condição crítica de fundo na emergência do Estado moderno. Por isso dizemos que a constituição de Estados absolutamente soberanos não prevaleceu sem competidores ou alternativas ao longo da história do aparecimento da instituição da soberania (Spruyt, 1994; Tilly, 1996). Da mesma forma, a história dos Estados nacionais sempre foi marcada por um contexto de cismas, de amargos conflitos e de disputas de autoridades que dominaram a Europa desde, pelo menos, o começo da Reforma. Hoje encontramos, certamente, novos desafios, novos constrangimentos e novas concorrências. Entretanto, considero muito cedo para se imaginar a perda do poder dos Estados, que têm se mostrado uma instituição flexível e adaptável.19

19 Considero aqui a própria soberania como instituição, segundo a concepção de Krasner (1988). Parto, neste artigo, de modo geral, de uma ampla noção de instituição, que vai além da noção explicativa da natureza de poderes materiais, estatais ou do interesse nacional, para servir na organização de interesses que surgem de idéia, crenças e identidades e fazem surgir padrões gerais de expectativas e restrições. 


\section{CRISES OU ADAPTAÇÕES?}

Na obra de Janice Thomson (1994), a autora analisa a transformação do sistema político medieval para o sistema de Estados soberanos. Segundo Thomson, o Estado soberano surgiu como uma necessidade de organização do espaço político que deveria suprir novas necessidades econômicas e de estruturação de poder e legitimação de interesses. Atores não-estatais como mercenários e piratas passaram a ameaçar interesses, antes compatíveis com estes procedimentos não soberanos de uso da força. Assim, situações involuntárias de intempéries e excessos de atores nãoestatais promoveram um grau de insegurança tal que a institucionalização de uma ordem que legitimasse o monopólio da violência se tornou conveniente e necessária.

Nesse contexto narrativo podemos compreender a criação do Estado nacional como uma estratégia de institucionalização de identidade de uma certa coletividade. Anthony Smith (1992) acrescenta sobre o Estado-Nação que este modelo político foi um projeto e não uma realidade perfeitamente verificável ao longo da modernidade. Ou seja, o que se descobre com a crise do Estado-Nação, não é que ele não é mais possível, mas que foi rompida uma intenção de se manter formalmente o conceito de Estado-Nação como um modelo universalmente realizável nos moldes de um Estado centralizado e legitimado sobre uma base nacional nítida. ${ }^{20}$

Sobre a "crise da soberania" ou a "crise do Estado-Nação", destacamos a contribuição de Charles Beitz (1991), por apresentar um percurso satisfatoriamente sistemático de argumentos sobre o problema das mudanças do alcance do poder dos Estados e das relações entre eles no fim do século XX. Em resumo, Beitz reforça que é apenas no âmbito do exer cício externo da soberania dos Estados contemporâneos que surgem suas novas dimensões problemáticas, logo, as necessidades de adaptabilidade. Assim, há um problema teórico (ou normativo), um problema político (ou institucional) e um problema legal (ou jurídico) a serem discutidos. Nessas condições, refletir sobre "a crise da soberania" implica refletir sobre a distinção entre autonomia e soberania e abordar essas três dimensões críticas que se referem respectivamente aos problemas do conceito de soberania, da crise do Estado-Nação (que é a organização institucional soberana pri-

20 Anthony D. Smith diz que a ideologia do Estado-Nação tanto "lançou o mapa geopolítico em uma tormenta, como acarretou uma busca infrutífera e destrutiva de algo que é inalcançável fora de algumas regiões abençoadas da Terra" (cf. Smith, 1992). 
vilegiada) e da crise dos mecanismos coercitivos modernos internacionais - que, por serem prioritariamente pacíficos, envolvem o direito internacional. Esses três problemas estão implicados na soberania de modo que é preciso reconhecer que há múltiplas faces e abordagens sobre a eventual crise do estabelecimento e da organização do poder político diante das transformações mundiais.

A crise do conceito de soberania, a distinção entre autonomia e soberania e os limites dos atributos dos Estados na condução da solução de problemas no ambiente da globalização, ficam revelados quando discutimos temas como direitos humanos, ecologia ou novas formas de associativismos internacionais. Principalmente porque esses temas não são novos, as circunstâncias e possibilidades de problemas e soluções é que são diferentes atualmente. Lutas pelo fim da escravidão, pelo direito à vida, ao voto e, mais recentemente, pelos direitos indígenas, trabalhistas, direito à infância e ao fim da pobreza - sempre deixaram claro que tentativas de assegurar bens da vida se revelaram como lutas políticas pela institucionalização de medidas de segurança para proteção de princípios, valores e idéias. Alguns destes direitos são protegidos de modo mais seguro e satisfatório no âmbito da jurisdição doméstica dos Estados e outros, mesmo requerendo a proteção doméstica, se asseguram cada vez mais a partir de mecanismos de proteção internacional. Esta é uma descoberta da década de 1950, forçosamente a partir da experiência de duas brutais guerras mundiais. Estamos seguindo uma trilha já aberta que vem ganhando melhores condições de efetividade e credibilidade. É o que vemos hoje a respeito da importância da regulação mínima internacional quanto a direitos trabalhistas, saúde, proteção de meio ambiente, comércio e principalmente, direitos humanos. Keck \& Sikkink (1998) investigam casos históricos, modernos e contemporâneos ${ }^{21}$, em que o ativismo além das fronteiras dos Estados foi fundamental para a incorporação nacional de certas mudanças, conseqüentemente, para um debate mais amplo sobre a transnacionalidade de direitos e de identidades.

Outros autores como: John Keane, Jean Cohen, Andrew Arato, Marlies Glasius, Helmut Anheier, Mary Kaldor, apenas para exemplificar - discutem o surgimento de uma sociedade civil global e o paradigma

${ }^{21}$ No período moderno, as autoras dão dois exemplos de importantes campanhas em que o ativismo internacional foi fundamental: o movimento abolicionista e a campanha do sufrágio feminino. Os três casos contemporâneos citados com destaque à ação de organizações internacionais são: direitos humanos, meio ambiente e direito à igualdade entre homens e mulheres. 
teórico para a análise deste novo ator internacional; identificam sua forma de atuação; enfim, discutem novos fenômenos da ação política de setores sociais que surgem independentemente de aparatos estatais. Neste contexto de reflexões, a teoria habermasiana tornou-se um instrumento teórico fundamental para novos rumos da teoria democrática a respeito da construção de novos conceitos de sociedade civil e de esfera pública. Por isso é que se pode dizer que esta nova esfera pública sugerida não é estatal e que a defesa de interesses privados não se resume à defesa de interesses econômicos. Eis aí um novo campo de batalha, uma nova perspectiva para a competição por espaços de poder e pelo aumento de força. As regras e interesses que se originam das idéias compartilhadas e valores que não dependem de uma razão estratégica, uma vez institucionalizadas, passam a ser fruto de luta pela mudança do sistema, que é estratégico e burocrático. ${ }^{22}$

\section{CONCLUSÕES}

Segundo Letícia Pinheiro (2000), é possível considerar as principais vertentes teóricas da análise de política internacional em um continuum que frisa tendências opostas em uma mesma plataforma que considera o Estado o ator fundamental das relações internacionais.

+ anarquia

- cooperação

\section{Hobbes}

Institucionalismo Neoliberal
- anarquia + cooperação

Fonte: Pinheiro, 2000

Figura 1 - Continuum de Pinheiro

22 Segundo Habermas há uma distinção entre dois modelos de racionalidade: racionalidade estratégica e racionalidade comunicativa. Em resumo, a racionalidade estratégica é a que está voltada para a lógica sistêmica das forças estratégicas do poder e do dinheiro, ou seja, existem dois subsistemas lógicos que são o Estado e o mercado. O "mundo da vida" para Habermas seria, em resumo, aquele através do qual a racionalidade comunicativa faz gerar condutas e organizações que têm na comunicação e não na estratégia sua coluna vertebral. Segundo Habermas, da mesma forma que o "mundo da vida" busca institucionalização e judicialização de seus princípios normativos (essa é uma tendência de busca de segurança), a lógica sistêmica penetra o mundo da vida (ou tende a penetrar, pois há um disputa de "espaços") em busca da "colonização", ou seja, da mercantilização e burocratização das relações humanas que devem ter na razão comunicativa sua via de democratização. Habermas crê que a democratização se dá pela via da institucionalização, mas é fato que a captura do mundo da vida acabaria com a publiscização e a liberdade necessárias para sua expansão. 
Em seu artigo, Pinheiro enfoca a política externa brasileira, mas seu "esquema" não é útil apenas nesse contexto. Na verdade, Pinheiro traça um continuum realista que inspira à complementação. Este artigo buscou enfocar o quanto temas de investigação política esbarram na necessidade de se verificar a interconexão entre o comportamento de setores sociais e o desenvolvimento político nacional. Cada vez mais o ativismo internacional têm tido condições para informar, divulgar, formar opinião, pressionar a adoção de políticas, mudanças normativas, influenciar interesses, preferências e comportamentos - por vezes até mesmo são capazes de causar mudança de percepção, procedimentos e políticas (Keck; Sikkink, 1998). A ação coletiva em redes, como mecanismos estratégicos e instrumentais em que surgem novas dimensões de ação, fluxo de informação, idéias e identidades, atualmente se tornou fundamental para as relações internacionais. Articulações que se fazem em rede eram objetos de estudo de outras disciplinas como antropologia e ciências sociais ${ }^{23}$ - mas as relações nodais transnacionais exigem uma revisão de sua importância.

Naturalmente, novos processos de mudança e influência política se forjam e buscam utilidade no campo das relações internacionais pela via de um tecido social que transpõe barreiras materiais (territoriais ou nacionais) e faz emergir novas demandas reflexivas a respeito de noções como cidadania ou espaço público. É fato que existem novos mecanismos para que setores da sociedade civil moldem estratégias de lutas por direitos e estes não são mais articulados dentro de Estados - porém, o que quero destacar é que eles não pretendem excluí-los.

Por fim, novos atores são novos players no campo das relações internacionais e com eles surgem novos processos de atuação política: associativismos transnacionais, identidades transnacionais, ações em rede etc. Assim, além de identificar o foco mais filosófico da importância da emergência de uma sociedade civil global e de uma esfera pública transnacional, verificamos que a institucionalização de novas demandas através de organizações não-estatais se tornou também uma estratégia competitiva dentro de novos espaços de conflito em que o interesse nacional deixou de ser monolítico e as tecnologias da globalização (comunicação, transportes etc.) se tornaram fatores determinantes de ação coletiva e aumento de poder.

${ }^{23}$ Para um interessante resumo sistemático da metodologia de redes no estudo de ações coletivas, cf. Scherer-Warren, 1999. 
Keck e Sikkink (1998) estabelecem uma tipologia das táticas de persuasão e pressão para a ação de indivíduos ${ }^{24}$, atores e grupos em redes transnacionais, com diferentes graus de influência ou sucesso. A boa performance de uma rede se revela na capacidade de penetrar as agendas políticas externas, passando por alguns estágios detalhados por Keck e Sikkink (1998), até atingir atores centrais (tomadores de decisão ou provedores de recursos), podendo finalmente, em um grau absoluto de sucesso, mudar o comportamento dos Estados diante da demanda em questão.

Na perspectiva de Arato e Cohen (1994), uma "descolonização" do mundo da vida pressupõe a capacidade da sociedade civil em articularse institucionalmente ${ }^{25}$, de modo a intermediar o poder do Estado e do mercado. No caso das networks, essas funcionam como processos de articulação e ação que atingem seus objetivos máximos também quando são capazes de mudar o comportamento dos Estados - como está dito. Sendo assim, é possível reconhecer nessa literatura, não apenas uma perspectiva idealista, que visa transformar o sistema internacional através da interação dos indivíduos (modelo kantiano), mas ainda podemos identificar semelhanças com o grotianismo, no que depende de uma transformação global pela via das instituições. Ou seja, não se pretende abandonar a soberania pelos indivíduos (como defendem as teses universalistas), mas aperfeiçoar a ordem internacional pelos indivíduos e pelas instituições - mantendo-se os Estados, mas reconhecendo-se a necessidade de ação individual transnacional para que se aperfeiçoem as instituições.

Com tudo isso, apenas como um exercício, poderíamos continuar a pensar a partir do continuum de Pinheiro (2000) e concluir que, se para o hobbesianismo menos cooperação combina com mais conflito e para o racionalismo grociano o aumento de cooperação está ancorado em uma situação anárquica menos fragmentada (ou menos anárquica), seguindo palavras de Keohane (1988; 1993), o institucionalismo neoliberal retrata a situação de interdependência que leva à seguinte combinação: aumento de conflito e aumento de cooperação.

Argumentos a favor ou contra a existência de consensos e identidades transnacionais constituindo-se em uma esfera pública não estatal não podem mais ser excluídos dos debates teóricos sobre relações internacionais e, principalmente, sobre a eventual mudança do papel dos Estados

\footnotetext{
24 São estratégias políticas da ação em rede: informação, simbologia, influência e accounta bility (para mais, cf. Keck \& Sikkink, 1998, p. 16).

25 Democratização, para Habermas, pressupõe institucionalização.
} 
- seja para refutar a tendência neo-universalista, seja para identificar vetores conciliatórios para uma "leitura institucionalista à direita", tomando-se como referência o continuum de Pinheiro (2000). Além de se tratar de um posicionamento teórico menos hobbesiano, que se filtra em uma tendência institucionalizante e regulatória das demandas, não se pressupõe apenas que os atores interessados são os Estados e as instituições, indivíduos também se tornaram atores interessados na constituição de instituições que representem suas preferências estrategicamente. Pinheiro (2000) propicia uma visualização didática importante para o debate teórico realista sobre a relação entre cooperação e anarquia e a participação dos Estados, instituições e indivíduos na ordem internacional. Assim, proponho como exercício de reflexão a seguinte retratação, tendo por base a idéia de Pinheiro (2000):

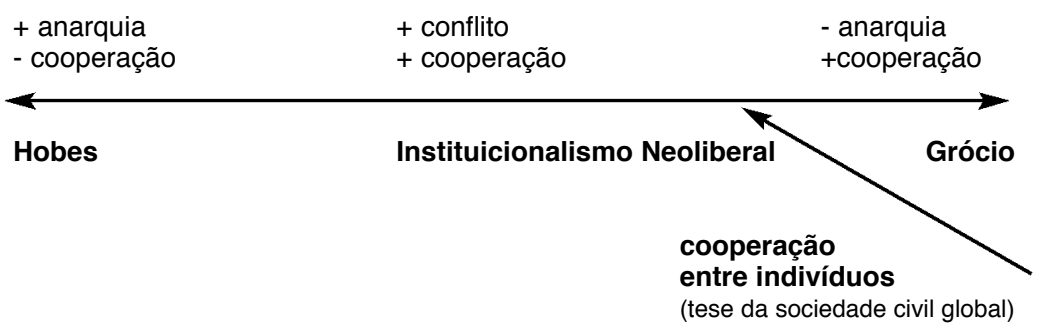

Figura 2 - Exercício de reflexão sobre o continuum de Pinheiro

O que pretendo reforçar com esse exercício de complementação da contribuição de Pinheiro é que, desde a perspectiva da constituição das networks ou do objetivo dos novos movimentos sociais, não se pretende substituir o poder dos Estados e sim "penetrá-lo" - invertendo-se a relação de influência e intervenção. A partir da atuação da sociedade civil em rede geram-se instituições que passam a jogar o jogo de cooperação e conflito, percebendo-se uma postura menos hobbesiana, mas nem por isso grociana, já que indivíduos (e instituições criadas a partir de interesses de grupos de indivíduos) - e não os Estados - é que fazem aparecer um novo ator: a sociedade civil global.

Há muito a ser debatido sobre as formas e condições inéditas de ocupação do espaço público e do ativismo político transnacional, mas é possível identificar uma diferença notável entre as tendências universalistas e a literatura a respeito da emergência de uma nova sociedade civil global: as instituições são importantes atores garantidores de interesses e, assim como o direito, funcionam como âncoras regulatórias que viabilizam a satisfação 
de demandas de indivíduos - desde o "mundo da vida". Por tudo isso, a linha diagonal proposta na Figura 2 representa que não apenas ações de Estados e forças internacionais, mas também de indivíduos, fazem surgir instituições que se relacionam segundo a perspectiva realista genética que prevê a não superação do conflito no campo da política internacional. Enfatizo isso porque a ação da sociedade civil no âmbito transnacional se institucionaliza e alimenta uma estratégia cooperativa próxima à noção de cooperação para o institucionalismo neoliberal. Uma cooperação estratégica que se diferencia da noção de cooperação de caráter societário (estatal) que as teses racionalistas clássicas (Grócio e Bull) consideram. Nem por isso as teses contemporâneas sobre a sociedade civil global devem ser confundidas com as tradicionais noções que defendem uma democracia absolutamente consensual, como o universalismo kantiano que considera a constituição de uma comunidade mundial ou de uma democracia cosmopolita. Como não prevejo o desaparecimento do papel primordial dos Estados nas relações internacionais, proponho uma leitura da realidade sobre a expansão da sociedade civil global a partir de perspectivas teóricas que reputam ao processo democrático um espaço dialógico, em que há discordância, competição e busca de institucionalização e segurança jurídica.

Os novos movimentos sociais, ativismos transnacionais, organizações de movimentos transnacionais e organizações não governamentais pressupõem um ambiente ordenado pela garantia de direitos mínimos que propiciem ação e participação, logo, reconhecem a importância de poderes tradicionais do Estado e do Direito. Assim, não precisamos esperar pelo fim absoluto do conflito, mas sim buscar realimentar a regra geral da ordem referida no continuum retratado, em que Estados e instituições, em maior ou menor grau, tendem a continuar a cooperar e competir.

A perspectiva racionalista levada ao extremo, como um tipo ideal, considera a possibilidade de existir um ethos societário entre os Estados que interagem mais intensamente (o que corresponde à tese liberal de Bull, 2002). Os novos debates sobre a construção de uma esfera pública não estatal nem sempre se mostram tão ambiciosos quanto ao reconhecimento de um ethos societário tão abrangente: transnacional (universalista) ou internacional. Entretanto, consideram o pluralismo e a multiplicidade de valores e interesses (menos amplos e mais complexos) capazes de gerar ação coletiva e instituições estratégicas - essa igualdade na diferença, assim como a defesa do interesse público que passa a ser o direito de defender "interesses parciais" ou individuais (políticas de identidade, questões de gênero, comportamento sexual, tradições locais, hob - 
bies etc.) é que estabelecem a gênese de novas disputas no espaço social. Mesmo quando o conteúdo da disputa é identidade ou solidariedade a respeito de qualquer universo cognitivo, o objetivo não é o da subversão da ordem dos Estados ou do direito nem a criação de valores interestatais comuns e sim a busca da organização e reprodução de culturas, de solidariedades e identidades diversas diante do Estado e do mercado; a sociedade civil se institucionaliza assim pela defesa do "mundo da vida".

Por tudo isso, a multiplicação dos canais de acesso ao sistema internacional, o crescimento da importância da ação de organizações internacionais, atores estatais e atores não-estatais, não-governamentais e não soberanos e, principalmente, os novos processos políticos intergovernamentais e transnacionais em que os indivíduos passam a ser atores fundamentais, vêm trazendo uma série de questionamentos sobre distinções e limites entre política doméstica e política externa ou entre realismo e utopismo.

As teorias constroem uma realidade, mas ninguém pode alguma vez dizer que é $a$ realidade. (...) Já disse o que são e o que não são teorias, mas não disse como as teorias são feitas. Como são feitas? A melhor resposta curta, mas que em nada ajuda, é esta: "criativamente". (Waltz, Teoria das Relações Internacionais, cap. I, 2002)

ANA PAULA B. TOSTES é Professora Visitante do Departamento de Ciência Política da USP

\section{REFERÊNCIAS BIBLIOGRÁFICAS}

ADLER, Emmanuel. (1999), "O construtivismo no estudo das relações internacionais". Lua Nova, $n^{\circ} .47$, p. 201-246.

ARATO, Andrew e COHEN, Jean. (1994). "Sociedade Civil e Teoria Social". In: AVRITZER, Leonardo. (Coord.) Sociedade Civil e Democratização, Belo Horizonte, Livraria Del Rey.

ARON, Raymond. (1996), Paz e guerra entre as nações. Brasília. Editora Universidade de Brasília.

AVRITZER, Leonardo. (1997), "Um desenho institucional para o novo associativismo". Lua Nova, vol. 39.

BEITZ, Charles R. (1991), "Sovereignty and Morality in International Affairs", In: HELD, D. (ed.), Political Theory Today, Stanford, Stanford University Press.

BOLI, John; THOMAS, George M. (1997), "World Culture in the World Polity: A Century of International Non-governmental Organization". American Sociological Review, v. 62, Issue 2, p. 171-190. 
BULL, H. (2002), A sociedade anárquica. São Paulo, Imprensa Oficial de São Paulo. CARR, Edward. (1981), Vinte Anos de Crise 1919-1939. Brasília, Ed. UnB/IOESP.

CHATFIELD, Charles. (1997), "Intergovernmental and Nongovernmental Associations to 1945". In: SMITH, Jackie e outros (ed.), Transnational Social Moviments and Global Politics. Solidarity Beyond the State. New York, Syracuse University Press, p. 19-41.

COHEN, Jean L. and ARATO, Andrew. ( Civil Society and Political Theory. The MIT Press, Cambridge, Massachussetts.

EDWARD, Michael. (2004), Civil Society. Cambridge, Cambridge University Press, p.1-53.

FINNEMORE, Martha. (1996), National Interests in International Society. Ithaca. Cornell University Press.

FONSECA Jr, Gelson. (1997), "Anotações sobre as condições do sistema internacional no limiar do século XXI: a distribuição dos pólos de poder e a inserção internacional do Brasil". Temas de Política Externa Brasileira II. São Paulo, Paz e Terra, vol. 1.

(1998), A legitimidade e outras questões internacionais. São Paulo, Paz e Terra.

GILPIN, Robert. (2001), Global Politics Economy: Understanding the International Economic order. Princepton, Princepton University Press.

(1987), The Political Economy of International Relations. Princeton, Princeton Universsity Press.

GLASIUS, M; KALDOR, M; ANHEIER, H. (2002), Global Civil Society. Oxford University Press, Oxford.

GLOBALIZAÇÃO, CRESCIMENTO E POBREZA. A visão do Banco Mundial sobre os efeitos da globalização. (2003), São Paulo, ed. Futura.

HABERMAS, J. (1988), Teoria de la Acción Comunicativa. Taurus, Madri.

JOSEPH, A. Camilleri; FALK, Jim. (1992), The End of Sovereignity? The Politics of a Shrinking and Fragmenting World. Aldershot, Edward Elgar Publishing Limited.

KALDOR, Mary; GLASIUS Marlies. (2002), "The State of Global Civil Society: before and after september 11", In: GLASIUS, Marlies; KALDOR, Mary; ANHEIER, Helmut (ed.). (2002), Gobal Civil Society 2002, Oxford, Oxford University Press, cap. 1, p. 3-33

KEANE, John. (1998), Civil Society. Old Images, New Visions. Stanford University Press, Stanford, California. (2003), Global Civil Society? Cambridge, Cambridge University Press.

KECK, Margaret E.; SIKKINK, Kathryn. (1998), Activists beyond Borders. Advocacy networks in International Politics, London, Cornell University Press.

KEOHANE, Robert O. (1988), Después de la hegemonía. Cooperación y discordia en la política económica mundial. Buernos Aires, Grupo Editor Latinoamericano.

(1993), Instituciones Internacionales y poder estatal. Buenos Aires, Grupo Editor Latinoamericano.

KEOHANE, Robert O.; NYE, Joseph S. Jr. (1989) "Realism and Complex Interdependence". In: WILLIAMS, Marc (ed.) International Relations in the Twentieth Century: A Reader. London, The Macmillan Press Ltd.

KRASNER, Stephen D. (1988) "Sovereignty. An Institutional Perspective". Comparative Political Studies, Newbury Park, Beverly Hills, London, New Delhi, Sage Publications, 21: (1), april, p. 66-94.

KRATOCHWIL, Friedrich. (1986), "Of systems, boundaries, and territoriality: An inquiry into the formation of the state system". World Politics, Princeton, Princeton University Press, vol. 39, n 1, october, p. 27-52. 
LAFER, Celso e FONSECA Jr., Gelson. (1997), "Questões para a diplomacia no contexto internacional das polaridades indefinidas" Temas de Política Externa Brasileira II. São Paulo, Paz e Terra, vol. 1.

NYE Jr., Joseph. (2002), Compreender Conflitos Internacionais. Lisboa, Gradiva.

PINHEIRO, Letícia. (2000), "Traídos pelo desejo: um ensaio sobre a teoria e a prática da política externa brasileira contemporânea. Contexto Internacional. Rio de Janeiro, v. 22, n. 2, p. 305-335, jul-dez.

ROBERTSON, Roland. (1995), "Glocalization: time-space and homogeneity-heterogeneity". In: FEATHERSTONE, M. e outros (ed.). Global Modernities, London, SAGE, p. 25-44.

SMITH, Anthony D. (1992), "Criação do Estado e Construção da Nação". In: HALL, J. (org.), Os Estados na História, Rio de Janeiro, Imago Editora.

SPRUYT, Hendrik. (1994), The Sovereign State and its Competitors. Princeton, Princeton University Press.

STOPFORD, John M.; SRANGE, Susan; HENLEY, John S. (1991), Rival States, Rival Firmas: Competitions for World Market Shares. Cambridge, Cambridge University Press.

STRANGE, Susan e outros. (1996), The Retreat of the State: the diffusion of Power in the World Economy. Cambridge, Cambridge University Press.

SINGER, Paul. (1997), "Globalização positiva e globalização negativa: a diferença é o Estado". Novos Estudos Cebrap, n 48, julho.

THOMSON, Janice. (1994), Mercenaries, Pirates and Sovereigns: State-building and Extraterritorial Violence in Eraly Modern Europe. Princeton, Princeton University Press.

TILLY, Charles. (1996), Coerção, Capital e Estados Europeus. São Paulo, ed. USP. (ed.) (1975), The Formation of National States in Western Europe. Princeton, New Jersey, Princeton University Press.

TOCQUEVILLE, Alexis de. (1997) O Antigo regime e a Revolução. trad. Yvonne Jean, Brasília, ed. Universidade de Brasília.

(1990) De la Democratie en Amérique. (edição histórica e crítica, revista e comentada por Eduardo Nolla), Paris, Librairie Philosophique J. Vrin, Tomos I e II.

UNION OF International Associations (UIA). (1988), Yearbook of International Organizations. vol. 25 1988-1989. Munich; Germany, K. G. Saur.

VILLA, R. A. D. (1999), "Formas de influência das ONGs na política internacional contemporânea". Revista de Sociologia e Política. UFPR, p. 21-34.

RISSE-KAPPEN, Thomas. (1994), "Ideas Do Not Float Reely: Transnational Coalitions, Democratic Structures, and the End of the Cold War". International Organization, v. 48, p. 185-214.

SCHERER-WARREN, Ilse. (1999), Cidadania sem fronteiras. Ações coletivas na era da globalização. São Paulo, ed. Hucitec.

WALTZ, Kenneth N. (2002), Teoria das Relações Internacionais. Lisboa, Gradiva. (2000). "Structural realism after the Cold War". International Security, vol. 25, no 1 (Summer), p. 5-41.

WALZER, Michael. (1997), On Toleration. New Haven and London, Yale University Press.

WENDT, A. (1999), Social Theory and International Politics. Cambridge, Cambridge University Press. 